\title{
An Efficient High Performance Voltage Decoupled Induction Motordrive With Excitation Control
}

Islam, S.M. Somuah, C.B.;Dept. of Electr. Eng., King Fahd Univ. of Pet.Miner., Dhahran;

Energy Conversion, IEEE Transaction on;Publication Date: Mar 1989;Vol: 4,Issue:

1

King Fahd University of Petroleum \& Minerals

http://www.kfupm.edu.sa

\section{Summary}

The state of the art in indirect slip frequency-controlled induction motor drive systems is fast response, high performance, voltage decoupling control. However, decoupling control needs to operate at a constant rotor flux, which makes energy conversion inefficient. A variable-flux decoupling model of a voltage-fed induction motor which provides optimal efficiency and quick response is proposed. An optimization scheme determines the flux level for maximum efficiency at any operating condition, and a coordination controller assures quick torque response without torque pulsations. Application to a $100 \mathrm{hp}$ and a $7.5 \mathrm{hp}$ motor shows that a substantial saving in controllable losses during low-load operation is possible while maintaining high performance

For pre-prints please write to:abstracts@kfupm.edu.sa

(c) Copyright: King Fahd University of Petroleum \& Minerals; 